\title{
Perbandingan Efektifitas dan Keamanan Parasetamol Intravena dan Ibuprofen Oral pada Penutupan Duktus Arteriosus Persisten pada Bayi Kurang Bulan
}

\author{
Oktaviliana Sari, ${ }^{*}$ Ria Nova, ${ }^{*}$ Herman Bermawi, ${ }^{*}$ Erial Bahar** \\ ${ }^{*}$ Bagian Kesehatan Anak, ${ }^{* *}$ Unit Penelitian Kesehatan Fakultas Kedokteran Universitas Sriwijaya/RS Moh. Hoesin, Palembang
}

Latar belakang. Duktus arteriosus persisten (DAP) pada bayi kurang bulan (BKB) dapat menimbulkan gangguan hemodinamika sehingga perlu segera ditutup. Salah satu cara penutupan adalah dengan obat penghambat siklooksigenase (COX), khususnya ibuprofen. Mengingat efek samping yang ditimbulkan ibuprofen, parasetamol yang bekerja menghambat peroksidase mulai diperkenalkan sebagai alternatif dengan efektifitas setara dan efek samping yang minimal.

Tujuan. Membandingkan efektifitas dan keamanan antara parasetamol intravena dan ibuprofen oral untuk penutupan DAP pada BKB. Metode. Uji klinis terbuka, acak terkontrol pada bayi dengan usia gestasi $\leq 37$ minggu yang dikonfirmasi DAP dengan menggunakan ekokardiografi. Dilakukan randomisasi blok untuk menerima parasetamol intravena atau ibuprofen oral. Hasil utama yang dinilai adalah respon terapi penutupan duktus arteriosus (DA), efek samping yang timbul, dan kejadian reopening.

Hasil. Penutupan DAP terjadi pada 33 dari $36(91,6 \%)$ BKB yang mendapat parasetamol intravena dan 29 dari $40(72,5 \%)$ yang mendapat ibuprofen oral $(\mathrm{p}=0,03)$. Pada kelompok ibuprofen, efek samping yang timbul berupa trombositopenia $(28,5 \%)$ dan perdarahan saluran cerna $(25,7 \%)$, sedangkan pada kelompok parasetamol intravena tidak dijumpai efek samping. Reopening terjadi hanya pada satu bayi di kelompok ibuprofen oral.

Kesimpulan. Parasetamol intravena lebih efektif dan lebih aman dibandingkan ibuprofen oral untuk penutupan DAP pada BKB. Sari Pediatri 2015;17(4):279-84.

Kata kunci: duktus arteriosus persisten, bayi kurang bulan, parasetamol intravena, ibuprofen oral

\section{The Comparison of Effectiveness and Safety between Intravenous Paracetamol and Oral Ibuprofen for Persistent Ductus Arteriosus in Preterm Infants}

\author{
Oktaviliana Sari, ${ }^{*}$ Ria Nova, ${ }^{*}$ Herman Bermawi, ${ }^{*}$ Erial Bahar**
}

\begin{abstract}
Background. Persistent ductus arteriosus (PDA) in preterm infants can cause hemodynamic disturbances, that it must be closed immediately. PDA can be closed using cyclooxygenase inhibitor agents (COX), mainly ibuprofen. Because the side effects, intravenous paracetamol, a peroxidase inhibitor was recently introduced as an alternative terapy for ductal closure with similar effectiveness and minimal side effects.

Objectives. To compare the effectiveness and safety of intravenous paracetamol and oral ibuprofen for PDA closure in preterm infants.

Methods. An open label randomized controlled study was done in seventy six preterm infants (gestational age $\leq 37$ weeks) with echocardiographically confirmed PDA. Infant were randomly assigned to received either intravenous paracetamol or oral ibuprofen. The main outcome was the success of ductal closure and secondary outcomes were adverse effects and reopening.

Results. PDA closure was achieved in 33 of $36(91.6 \%)$ infants receiving intravenous paracetamol and in 29 of 40 (72.5\%) infants receiving oral ibuprofen $(\mathrm{p}=\mathbf{0 . 0 3})$. In the ibuprofen group, thrombocytopenia and gastrointestinal bleeding were found in $28.5 \%$ and $25.7 \%$ infants respectively, while in the paracetamol group, no adverse effect was observed. There was one infant who had reopening of PDA in the ibuprofen group.
\end{abstract}

Conclusion. Intravenous paracetamol is more effective and safer for ductal closure in premature infants. Sari Pediatri 2015;17(4):27984.

Keywords: persistent ductus arteriosus, preterm infants, intravenous paracetamol, oral ibuprofen

\footnotetext{
Alamat korespondensi: Dr. Oktaviliana Sari. Bagian Kesehatan Anak, Fakultas Kedokteran Universitas Sriwijaya, Jl. Jenderal Sudirman KM 3,5

Palembang, Indonesia. Email:fahmiokta_dr@yahoo.com
} 


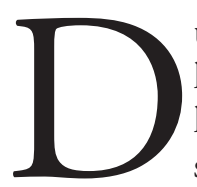
uktus arteriosus persisten (DAP) adalah kelainan kongenital yang ditandai adanya kegagalan penutupan duktus arteriosus segera setelah lahir. ${ }^{1}$ Kelainan ini sering dijumpai pada bayi kurang bulan dengan insiden 8 per 1000 kelahiran, sedangkan insiden pada bayi cukup bulan (BCB) lebih kecil yaitu, 1 per 2000 kelahiran. $^{2}$ Di Departemen Ilmu Kesehatan Anak (IKA) Rumah Sakit Cipto Mangunkusumo (RSCM), Jakarta insiden DAP pada bayi kurang bulan (BKB) dilaporkan 32\%, ${ }^{3}$ sedangkan di Departemen IKA Rumah Sakit Moh. Hoesin (RSMH), Palembang dilaporkan insiden pada bayi usia gestasi $<37$ minggu $58,7 \%{ }^{4}$

Secara fungsional, duktus arteriosus (DA) menutup pada umur 10-15 jam setelah lahir, tetapi banyak hal yang memengaruhi penutupan DA, seperti usia gestasi dan berat badan lahir. ${ }^{5}$ Penutupan DA secara spontan hanya terjadi pada $34 \%$ BKB. ${ }^{6,7}$ Penutupan spontan DAP tanpa sindrom gawat nafas pada $\mathrm{BKB}$ sebesar $10 \%$ pada hari ke- $1,60 \%$ hari ke-2, $85 \%$ hari ke-3 dan 97\% hari ke-4. Apabila penutupan spontan tidak terjadi pada hari ke-4 maka akan menjadi duktus arteriosus persisten. ${ }^{8}$

Gangguan hemodinamika banyak dialami BKB dengan DAP. Gangguan hemodinamika akan memperberat masalah lain yang menyertai BKB sehingga akan meningkatkan morbiditas dan mortalitas. ${ }^{9}$ Duktus arteriosus persisten pada BKB yang tidak tertutup akan berdampak pada peningkatan resistensi paru yang berhubungan dengan gangguan hemodinamik, di antaranya meningkatkan kejadian diplasia bronkopulmoner, menurunnya aliran darah ke otak yang akan meningkatkan risiko terjadinya perdarahan intraventrikular, menurunkan aliran darah ke saluran pencernaan sehingga dapat meningkatkan kejadian enterokolitis nekrotikan. ${ }^{9,10}$ Oleh karena itu, DAP pada BKB perlu ditutup dengan segera.

Salah satu cara penutupan DAP pada BKB adalah menggunakan obat yang bekerja sebagai inhibitor prostaglandin. Obat yang saat ini rutin digunakan adalah ibuprofen, suatu penghambat siklooksigenase (COX). Penelitian sebelumnya yang dilakukan di $\mathrm{RSMH}^{11}$ dan di Massachusetts ${ }^{12}$ menunjukkan bahwa pemberian ibuprofen efektif dalam penutupan DAP pada BKB. Walaupun terbukti efektif, penggunaan ibuprofen dapat menimbulkan efek samping, seperti gangguan fungsi ginjal, perdarahan gastrointestinal, dan enterokolitis nekrotikan. ${ }^{9,10}$

Akhir-akhir ini diperkenalkan sediaan lain yang tidak memiliki efek vasokonstriksi perifer yang dapat digunakan untuk menutup duktus arteriosus, yaitu parasetamol, suatu penghambat peroksidase yang bekerja mengurangi kosubstrat sehingga terjadi gangguan pembentukan prostaglandin yang memicu konstriksi otot DA. ${ }^{13}$ Dosis parasetamol intravena yang diberikan pada BKB dengan DAP adalah $15 \mathrm{mg} / \mathrm{kgbb} /$ kali setiap 6 jam dengan tingkat keberhasilan mencapai $87,5 \%$ dan tidak terlihat adanya efek samping. ${ }^{14}$ Bahkan, pemberian parasetamol efektif pada BKB dengan DAP yang tidak berespon atau memiliki kontraindikasi penggunaan ibuprofen. ${ }^{15,16}$ Berdasarkan pertimbangan manfaat, pengalaman, dan penelitian klinis dalam penggunaan parasetamol intravena pada BKB di Indonesia yang masih sangat terbatas dan belum pernah dilakukan di RSMH maka peneliti menganggap perlu melakukan penelitian ini.

\section{Metode}

Penelitian uji klinik terbuka untuk membandingkan efektivitas dan keamanan parasetamol intravena dan ibuprofen oral dalam penutupan duktus arteriosus pada BKB. Pengambilan sampel dilakukan di Divisi Neonatologi Departemen Kesehatan Anak RS Moh. Hoesin Palembang dari bulan Maret sampai September 2014. Penelitian ini telah disetujui oleh Komite etik penelitian kesehatan Rumah Sakit Mohammad Hoesin dan Fakultas Kedokteran Universitas Sriwijaya Palembang Indonesia. Bayi yang diikutsertakan pada penelitian ini telah mendapatkan persetujuan tertulis dari orangtua. Kriteria inklusi adalah semua bayi kurang bulan (umur kehamilan <37 minggu) yang dirawat di Divisi Neonatologi Departemen Kesehatan Anak RS Moh. Hoesin Palembang, berusia $\geq 48$ jam pada saat penelitian mulai dilakukan dan didiagnosis DAP melalui pemeriksaan ekokardiografi. Kriteria eksklusi adalah bayi dengan kelainan ginjal, peningkatan kadar SGOT/SGPT lebih dari dua kali, penyakit jantung ductal dependent, jumlah trombosit $<50000 / \mathrm{mm}^{3}$, enterokolitis nekrotikan, perdarahan peri intraventrikular (PPIV) derajat III-IV, sepsis neonatorum, dan hiperbilirubinemia.

Sampel diacak dengan cara melakukan randomisasi blok. Ditentukan blok yang seimbang untuk setiap enam subyek. Kemudian sampel dirandomisasi untuk mendapat parasetamol atau ibuprofen berdasarkan tabel sekuens. Parasetamol intravena diberikan dengan 
dosis $15 \mathrm{mg} / \mathrm{kgbb} / 6$ jam selama tiga hari berturutturut, ibuprofen oral diberikan dengan dosis awal $10 \mathrm{mg} / \mathrm{kg}$, dilanjutkan $5 \mathrm{mg} / \mathrm{kgbb}$ pada 24 dan 48 jam berikutnya. Sebelum dan sesudah pengobatan dilakukan pemeriksaan darah lengkap, fungsi ginjal, diuresis, fungsi hati, bilirubin dan ultrasonografi (USG) kepala. Hasil utama yang dinilai adalah tingkat keberhasilan penutupan duktus arteriosus, kejadian reopening dan efek samping yang timbul.

\section{Hasil}

Selama periode penelitian didapatkan 128 BKB dengan usia kehamilan kurang dari 37 minggu. Kriteria inklusi BKB 76 (59,3\%) bayi dan sisanya dieksklusi. Tidak ada perbedaan dalam hal karakteristik umum pada kedua kelompok (Tabel 1).

Tabel 1.Karakteristik umum kelompok terapi $(\mathrm{n}=76)$

\begin{tabular}{lcc}
\hline Karakteristik & $\begin{array}{c}\text { Ibuprofen } \\
(\mathrm{n}=40)\end{array}$ & $\begin{array}{c}\text { Parasetamol } \\
(\mathrm{n}=36)\end{array}$ \\
\hline Jenis kelamin & & \\
$\quad$ Laki-laki & 8 & 6 \\
$\quad$ Perempuan & 32 & 30 \\
Umur (jam) & & \\
$\quad$ Rerata (SB) & $63,5(15,9)$ & $55,9(16,0)$ \\
Usia gestasi (minggu) & & \\
$\quad$ Rerata (SB) & $30,98(2,4)$ & $30,17(1,9)$ \\
Berat badan lahir (gram) & 1662,5 & 1512,5 \\
$\quad$ Rerata (SB) & $(248,7)$ & $(263,5)$ \\
Gangguan pernafasan (\%) & & \\
$\quad$ Tidak ada & $6(15)$ & $11(30,5)$ \\
BP & $2(5)$ & $0(0)$ \\
PMH & $31(77,5)$ & $23(63,8)$ \\
TTN & $1(2,5)$ & $2(5,5)$ \\
Ekokardiografi (\%) & & \\
Ukuran DAP & & \\
Kecil & $1(2,5)$ & $1(2,5)$ \\
Moderat & $34(85)$ & $34(85)$ \\
Besar & $5(12,5)$ & $1(2,5)$ \\
Kelainan jantung & & \\
Tidak ada & $36(90)$ & $31(86,2)$ \\
TR & $3((7,5)$ & $4(11,1)$ \\
PFO & $1(2,5)$ & $1(2,5)$ \\
\hline
\end{tabular}

BP: bronkopneumonia; PMH: penyakit membran hialin; TTN: transient tachypnea of the newborn; TR: Trikuspid regurgitasi; PFO: Patent Foramen Ovale
Pada masing-masing kelompok subjek yang diterapi menggunakan parasetamol intravena $(n=36)$ dan ibuprofen oral $(n=40)$, dilakukan ekokardiografi pada hari ke-4 setelah diagnosis untuk melihat respon terapi berupa terjadi atau tidaknya penutupan DA. Pada kelompok terapi ibuprofen oral terdapat lima bayi dinyatakan drop out dengan rincian dua bayi meninggal sebelum penelitian selesai dengan penyebab kematian berupa perdarahan paru karena penyakit membran hialin (PMH) dan tiga bayi dihentikan pengobatan selanjutnya karena timbul komplikasi berupa perdarahan saluran cerna sebelum menyelesaikan terapi tiga dosis. Pada analisis intention to treat (Tabel 2), DAP menutup pada $33(91,6 \%)$ bayi yang diberikan parasetamol intravena dan $29(72,5 \%)$ pada bayi yang diberikan ibuprofen oral $(\mathrm{p}=0,03)$.

Pada BKB yang diterapi menggunakan parasetamol intravena tidak dijumpai efek samping. Sebaliknya, pada kelompok terapi ibuprofen oral didapatkan efek samping obat berupa trombositopenia pada 10 $(28,5 \%)$ bayi dan perdarahan saluran cerna ringan pada $9(25,7 \%)$ bayi, yaitu ditemukannya cairan berwarna kecoklatan yang mengalir dari pipa orogastrik yang berhenti setelah dipuasakan beberapa waktu. Secara keseluruhan, efek samping lebih banyak ditemukan pada penggunaan ibuprofen dibandingkan parasetamol (Tabel 3).

Pada 19 bayi yang mendapat ibuprofen mengalami efek samping, adanya penyakit penyerta ditemukan

Tabel 2. Perbandingan respon terapi antara kelompok parasetamol intravena dan ibuprofen oral setelah pemberian tiga dosis obat $(\mathrm{n}=76)$

\begin{tabular}{|c|c|c|c|}
\hline \multirow[b]{2}{*}{$\begin{array}{l}\text { Kelompok } \\
\text { Terapi }\end{array}$} & \multicolumn{2}{|c|}{ Respon terapi (n) } & \multirow[b]{2}{*}{$\mathrm{p}^{*}$} \\
\hline & $\begin{array}{c}\text { Berhasil } \\
(n=40)\end{array}$ & $\begin{array}{c}\text { Tidak berhasil } \\
(\mathrm{n}=36)\end{array}$ & \\
\hline Parasetamol & 33 & 3 & 0,03 \\
\hline Ibuprofen & 29 & 11 & \\
\hline
\end{tabular}

*Uji kai kuadrat

Tabel 3. Hubungan antara efek samping obat dengan jenis terapi $(\mathrm{n}=71)$

\begin{tabular}{lcccc}
\hline Obat & ESO $(+)$ & ESO $(-)$ & Jumlah & $\mathrm{p}^{*}$ \\
\hline Parasetamol & 0 & 36 & 36 & $<0,001$ \\
Ibuprofen & 19 & 16 & 35 & \\
\hline${ }^{*}$ Uji kai kuadrat & & & &
\end{tabular}


Oktaviliana Sari dkk: Perbandingan efektifitas dan keamanan parasetamol intravena dan ibuprofen oral pada penutupan DAP pada BKB

Tabel 4. Evaluasi hasil laboratorium antara kelompok terapi parasetamol intravena dan ibuprofen oral setelah pengobatan satu siklus obat

\begin{tabular}{|c|c|c|c|c|c|c|c|}
\hline \multirow[b]{2}{*}{ Pengukuran } & \multicolumn{2}{|c|}{ Parasetamol intravena } & \multirow[b]{2}{*}{$\mathrm{p}^{*}$} & \multicolumn{2}{|c|}{ Ibuprofen oral } & \multirow[b]{2}{*}{$\mathrm{p}^{*}$} & \multirow[b]{2}{*}{$\mathrm{p}^{* *}$} \\
\hline & $\begin{array}{l}\text { Sebelum terapi } \\
\text { (SB) }\end{array}$ & $\begin{array}{l}\text { Setelah terapi } \\
(\mathrm{SB})\end{array}$ & & $\begin{array}{l}\text { Sebelum terapi } \\
\text { (SB) }\end{array}$ & $\begin{array}{l}\text { Setelah terapi } \\
(\mathrm{SB})\end{array}$ & & \\
\hline Kreatinin $(\mathrm{mg} / \mathrm{dL})$ & $0,61(0,09)$ & $0,68(0,12)$ & 0,06 & $0,64(0,1)$ & $0,71(0,08)$ & 0,08 & 0,9 \\
\hline Diuresis $(\mathrm{ml} / \mathrm{kg} / \mathrm{h})$ & $2,31(0,16)$ & $2,12(0,21)$ & 0,1 & $2,2(0,14)$ & $2,18(0,11)$ & 0,2 & 0,5 \\
\hline Bilirubin Total (mg/dL) & $4,36(0,73)$ & $4,8(0,69)$ & 0,09 & $5,4(0,69)$ & $5,8(0,71)$ & 0,31 & 0,92 \\
\hline SGOT (U/L) & $46,1(7,22)$ & $46,4(6,42)$ & 0,27 & $43,1(6,12)$ & $46,9(6,21)$ & 0,09 & 0,2 \\
\hline SGPT (U/L) & $43,4(6,21)$ & $44,6(6,80)$ & 0,18 & $44,6(7,5)$ & $48,2(6,62)$ & 0,06 & 0,8 \\
\hline
\end{tabular}

* uji t berpasangan; ** uji t tidak berpasangan untuk parameter laboratorium setelah pengobatan

pada semua bayi. Sementara pada 16 bayi yang tidak mengalami efek samping, penyakit penyerta ditemukan pada 13 bayi. Setelah dilakukan uji statistik, didapatkan kejadian efek samping tidak berbeda antara kelompok dengan penyakit penyerta dan tanpa penyakit penyerta (uji kai kuadrat, $\mathrm{p}=0,08$ ). Penyakit penyerta pada subyek kelompok ibuprofen yang mengalami efek samping yaitu TTN (satu bayi), PMH (17 bayi) dan bronkopneumoni (satu bayi).

Tidak terdapat satu pun bayi yang mengalami oliguria. Pada kedua kelompok pengobatan tidak terjadi perubahan bermakna dalam hasil pemeriksaan laboratorium fungsi hati dan ginjal sebelum dan sesudah obat diberikan, dan juga tidak berbeda bermakna antara kedua kelompok (Tabel 4). Pemantauan efek samping lainnya adalah dengan melihat perubahan derajat PPIV dengan USG transfontanela. Pada kelompok parasetamol terdapat 11 bayi dengan PPIV grade I, sedangkan pada kelompok ibuprofen terdapat 9 bayi dengan PPIV grade I, dan 3 bayi dengan PPIV grade II. Setelah pemberian obat, tidak terdapat peningkatan derajat PPIV pada kedua kelompok.

Dilakukan penilaian untuk mengevaluasi terbukanya kembali (re-opening) duktus arteriosus yang telah menutup. Subyek dengan DAP yang telah tertutup diperiksa ulang dengan ekokardiografi dua hari setelah siklus obat pertama diberikan. Pada kelompok ibuprofen terdapat satu bayi yang mengalami re-opening dari 29 bayi, sedangkan pada kelompok parasetamol tidak ada yang mengalami re-opening (uji kai kuadrat, $\mathrm{p}=0,001$ ).

\section{Pembahasan}

Penelitian ini dirancang untuk membandingkan efektivitas dan keamanan antara parasetamol intravena dan ibuprofen oral pada penutupan DAP pada BKB. Penelitian serupa belum pernah dilakukan sebelumnya di Palembang. Angka prevalensi DAP pada bayi dengan usia gestasi <37 minggu adalah 59,3\% (76/128). Hasil tersebut hampir sama dengan penelitian sebelumnya. Di Ankara, Turki, tahun 2014 Oncel dkk ${ }^{17}$ melaporkan kejadian DAP pada BKB 46\%. Di RSCM Jakarta dilaporkan angka yang lebih kecil, yaitu 32\%. ${ }^{3}$ Laporan dari RSMH satu tahun sebelumnya didapatkan angka kejadian yang sama dengan penelitian ini. ${ }^{4}$

Pada kelompok terapi parasetamol intravena, penutupan DA terjadi pada 33 dari 36 bayi dan pada ibuprofen oral terjadi pada 29 dari 40 bayi setelah pemberian tiga dosis obat. Penelitian terdahulu yang dilakukan oleh Oncel $\mathrm{dkk}^{15}$ menemukan keberhasilan penutupan DAP serupa dengan parasetamol intravena yaitu sebesar $87,5 \%$ tanpa adanya efek samping. Parasetamol intravena juga efektif pada DAP yang gagal menutup dengan pemberian ibuprofen. ${ }^{16}$

Penilaian re-opening dua hari setelah siklus pertama pengobatan dilakukan untuk mengevaluasi DA yang terbuka kembali setelah menutup. Re-opening tidak ditemuan pada kelompok parasetamol dan ditemukan pada satu bayi $(3,4 \%)$ dari kelompok ibuprofen. Dang $\mathrm{dkk}^{18}$ melaporkan terjadinya re-opening dengan terapi parasetamol pada lima $(7,7 \%)$ bayi dan dengan pemberian ibuprofen pada enam $(9,5 \%)$ bayi.

Kami tidak menjumpai efek samping dengan penggunaan parasetamol intravena. Temuan tersebut sesuai dengan daftar pustaka yang menyatakan bahwa penggunaan parasetamol intravena dengan dosis 15 $\mathrm{mg} / \mathrm{kgbb} / \mathrm{kali}$ tiap 6 jam tidak mengakibatkan efek samping. ${ }^{14}$ Hammerman $\mathrm{dkk}^{16}$ melaporkan tidak terjadi efek vasokonstriksi perifer pada pemberian parasetamol terhadap BKB dengan DAP dan dapat diberikan pada pasien yang memiliki kontraindikasi 
terhadap penggunaan ibuprofen, bahkan hingga usia 35 hari. Efek samping, berupa perforasi saluran cerna, oliguria, gangguan fungsi trombosit, intoleransi hepatic, dan hiperbilirubinemia juga tidak ditemukan. Hal tersebut serupa dengan penelitian terdahulu. ${ }^{19,22}$

Pada kelompok terapi ibuprofen oral, efek samping yang dijumpai adalah trombositopenia pada $28,5 \%$ bayi, tetapi sampai akhir pemantauan tidak ada bayi yang dilakukan tranfusi trombosit. Perdarahan saluran cerna derajat ringan terjadi pada $25,7 \%$ bayi, berupa ditemukannya cairan berwarna kecoklatan yang mengalir dari pipa orogastrik. Segera setelah efek samping itu muncul maka bayi ditata laksana sesuai dengan standar operasional prosedur perdarahan saluran cerna di Divisi Neonatologi RSMH Palembang. Pada penelitian kami tidak dijumpai perdarahan saluran cerna berat (hematoskezia, enterokolitis nekrotikan).

Ibuprofen sebagai penghambat siklooksigenase efektif untuk penutupan DAP, tetapi dapat menimbulkan efek samping, seperti perdarahan gastrointestinal dan enterokolitis nekrotikan. ${ }^{10}$ Dari penelitian sebelumnya ditemukan efek samping ibuprofen pada BKB berupa hiperbilirubinemia (35\%), ${ }^{18}$ trombositopenia (25\%), ${ }^{11}$ perdarahan saluran cerna $(2,5-12,6 \%),{ }^{17,18,20}$ NEC $(3,6 \%),{ }^{20}$ dan perforasi usus spontan $(3 \%) .{ }^{21}$ Pada penelitian kami, kejadian efek samping keseluruhan secara bermakna lebih besar pada pemberian ibuprofen oral dibandingkan parasetamol intravena.

Penelitian ini menunjukkan bahwa parasetamol lebih efektif dan aman dibandingkan ibuprofen untuk penutupan DAP pada BKB. Keterbatasan penelitian ini adalah pemberian terapi dan penilaian penutupan DAP dalam jangka waktu lebih panjang, misalnya tujuh hari, tidak dilakukan. Pemakaian parasetamol intravena juga belum banyak digunakan dalam penutupan DAP pada BKB karena harga yang mahal dan keterbatasan tenaga medis dalam melakukan pemasangan infus. Dengan demikian, sebaiknya dilakukan penelitian yang menilai apakah parasetamol oral sama efektif dan amannya dengan parasetamol intravena dalam penutupan DAP pada BKB.

\section{Kesimpulan}

Penutupan duktus arteriosus persisten pada kelompok terapi parasetamol intravena lebih banyak dibanding ibuprofen oral. Re-opening terjadi pada satu bayi pada kelompok ibuprofen. Efek samping berupa trombositopeni dan perdarahan saluran cerna hanya terjadi pada kelompok terapi ibuprofen oral.

\section{Daftar pustaka}

1. Hammerman C, Bin-Nun A, Kaplan M. Managing the patent ductus arteriosus in the premature neonate: a new look at what we thought we knew. Semin Perinatol 2012;36:130-8.

2. Schneider DJ, Moore JW. Patent ductus arteriosus. Circulation 2006;114:1873-82.

3. Deselina B, Putra ST, Suradi R. Prevalence of patent ductus arteriosus in premature infants at the neonatal ward, Cipto Mangunkusumo Hospital, Jakarta. Paediatr Indones 2004;44:223-7.

4. Novia B, Ria N, Julniar MT, Theodorus. Risk factors for patent ductus arteriosus in preterm neonates. Paediatr Indones 2014;54:132-6.

5. Sasi A, Deorari A. Patent ductus arteriosus in aterm infants. Paediatr Indones 2011;48: 301-8.

6. Sekar KC, Corff KE. Treatment of patent ductus arteriosus: indomethacin or ibuprofen. J Perinatol 2008;28:60-2.

7. Herrman, K., C. Bose, K. Lewis, M. Laughon. Spontaneous closure of the patent ductus arteriosus in very low birth weight infants following discharge from the neonatal unit. Arch Dis Child Fetal Neonatal ed 2009;94:48-50.

8. Mark D, Reller, Mary J,Rice MD. Reviews of studies evaluating ductal patency in the premature infant. J Pediatr 1993;122:S59-62.

9. S.Noori. Patent ductus arteriosus in the preterm infant: to treat or not to treat. J Perinatol 2010;30:31-7.

10. Yurtutan S, Oncel MY, Arayici S, Uras N, Altug N, Erdeve O, Dilmen U. A different first choice drug in medical management of patent ductus artriosus:oral paracetamol. J Matern Fetal Med 2013;26:825-7.

11. Yosy DS, Ria N, Herman B. Ibuprofen versus indomethachin for persistent ductus arteriosus closure in preterm infants. Pediatr Indones 2012;53:138-43.

12. Van Overmeire B, Smets K, Lecoutere D, van de Broek H, Weyler J, De Groote K, Langhendries JP. A comparison of ibuprofen and indomethacin for closure of patent ductus arteriosus. N Engl J Med 2000;33:67481.

13. Allegart K, Anderson B, Simons S. Paracetamol to induce ductus arteriosus closure : is it valid? Arch Dis Child 2013;98:462-6. 
14. Oncel MY, Yurttutan S, Degirmencioglu H. Intravenous paracetamol treatment in the management of patent ductus arteriosus in extremely low birth weight infants. J Pediatr 2013;166-9.

15. Oncel MY, Yurtutan S, Degirmencioglu H, Uras N, Altug $\mathrm{N}$, Erdeve O. Intravenous paracetamol treatment in the management of patent ductus arteriosus in extremely low birth weight infant. Neonatology 2013;103:166-9.

16. Hammerman C, Bin-Nun A, Markovitch E, Schimmel MS, Kaplan M, Fink D. Ductal closure with paracetamol: a suprising new approach to patent ductus arteriosus treatment. Pediatrics 2011;128:1618-21.

17. Oncel MY, Yurtutan S, Erdeve O, Uras N, Altug N. Oral paracetamol versus oral ibuprofen in management of patent ductus arteriosus in preterm infants : A randomized controlled trial. J Pediatr 2014;164:510-4.

18. Dang D, Dongxuan W, Chuan Z, Wenli Z, Qi Z.
Comparison of paracetamol versus ibuprofen in premature infants with patent ductus arteriosus : a randomized controlled trial. PLoS ONE 2013;8:e77888.

19. American Academy of Pediatrics Committe on Drugs. Acetaminophen toxicity in children. Pediatrics 2001;108:1020-4.

20. Gokmen T, Erdeve O, Altug N, Oguz SS, Uras N, Dilmen U. Efficacy and safety of oral versus intravenous ibuprofen in very low birth weight infants with patent ductus arteriosus. J Pediatr 2011;158:549-54.

21. Tath MM, Kumral A, Duman N, Demir K, Gurcu O, Ozkan H. Spontaneous intestinal perporation after oral ibuprofen treatment of patent ductus arteriosus in VLBW. Acta Paediatr 2004;93:999-1001.

22. Anderson BJ, Allegaert K. Intravenous neonatal paracetamol dosing: the magic of 10 days. Paediatr Anaesth 2009; 19:289-95. 